09,12

\title{
Фотолюминесценция гетероструктур CdTe/ZnTe c номинальными толщинами слоев CdTe от 1 до 8 монослоев, выращенных методом атомного наслаивания
}

\author{
(C) В.Ф. Агекян ${ }^{1}$, А.Ю. Серов ${ }^{1}$, Н.Г. Философров ${ }^{1}$, G. Karczewski ${ }^{2}$ \\ ${ }^{1}$ Санкт-Петербургский государственный университет, \\ Санкт-Петербург, Россия \\ ${ }^{2}$ Institute of Physics, Polish Academy of Sciences, \\ Warsaw, Poland \\ E-mail: v.agekyan@spbu.ru
}

Поступила в Редакцию 27 января 2020 г.

В окончательной редакции 28 января 2020 r.

Принята к публикации 28 января 2020 г.

\begin{abstract}
Исследована люминесценция слоев СdТе с номинальной толщиной 1, 2, 4 и 8 монослоев (MC), выращенных методом атомного наслаивания в матрице ZnTe. Показано, что слои толщиной 1 и $2 \mathrm{MC}$ проявляют свойства однородных слоев, в то время как слои с толщиной 4 и $8 \mathrm{MC}$ являются планарными массивами квантовых точек (КТ). Размеры КТ и их размерная дисперсия возрастают при увеличении номинальной толщины слоя СdTe. Форма спектров возбуждения люминесценции слоя СdTе в этих образцах сильно различается. Показано, что в зависимости от энергетического расстояния между экситонными уровнями слоев CdTe и матрицы ZnTe сильно изменяется соотношение вкладов в перенос энергии экситона ZnTe и носителей заряда, не связанных в экситон.
\end{abstract}

Ключевые слова: гетероструктуры II-VI, экситоны, люминесценция, перенос энергии.

DOI: 10.21883/FTT.2020.06.49352.011

\section{1. Введение}

Полупроводниковые гетероструктуры, содержащие двумерные квантовые ямы (КЯ) и квантовые точки (КТ), являются в настоящее время базовыми материалами для устройств оптоэлектроники, в первую очередь, лазеров и фотодетекторов. В случае существенного различия постоянных решетки материалов, образующих гетероструктуру, на интерфейсах возникают напряжения, способные сильно влиять на строение гетероструктуры. Эта проблема особенно актуальна для тонкого слоя, встроенного в широкозонную матрицу. После нанесения определенного количества вещества в таком слое возникают неоднородности, и, как правило, формируется планарный массив КТ, имеющих значительную размерную дисперсию. Реальное строение узкозонного слоя определяет излучательные свойства гетероструктуры энергетическое положение и ширину полосы люминесценции, ее квантовый выход, кинетику и температурную зависимость, пороговый ток лазерного устройства и т.д. Преобразование однородного слоя в ансамбль КТ сопровождается релаксацией напряжений, при этом гетероструктуры становятся свободными от дислокаций.

Сведения о реальной структуре тонкого слоя, которая зависит от элементного состава гетероструктуры, номинальной толщины слоя и технологии его роста, можно получить методами электронной микроскопии и оптической спектроскопии. Данные ряда работ [1-9] для гетероструктур типа II-VI, в частности, для системы
$\mathrm{CdTe} / \mathrm{ZnTe}$ с одной и той же номинальной толщиной узкозонного слоя, существенно различаются относительно энергетического положения и формы полосы излучения. Это свидетельствует о сильной зависимости реального строения тонкого слоя от технологических условий его формирования. Для системы CdTe/ZnTe эта проблема актуальна, в частности, в связи с интересом к КТ $\mathrm{CdTe}$, содержащим точно контролируемое количество магнитных ионов $\mathrm{Mn}^{2+}[10]$.

В настоящей работе изучается люминесценция серии образцов CdTe/ZnTe с номинальными толщинами слоев $\mathrm{CdTe} 1,2,4$ и 8 монослоев (MC), далее это образцы №№1, 2, 3 и 4 соответственно. Существенным моментом является то, что толстые барьерные слои ZnTe выращивались методом молекулярно-пучковой эпитаксии (MBE), а тонкие слои CdTe - методом атомного наслаивания (ALD).

\section{2. Результаты и их обсуждение}

На рис. 1 показаны спектры люминесценции образцов № 1-4 и спектр отражения образца № 2. На фоне интерференционных полос спектра отражения образцов № 1 и № 2 есть особенность, соответствующая экситонному резонансу слоя СdTe, которая в спектрах отражения образцов № 3 и № 4 не наблюдается вследствие сильного уширения их экситонных резонансов. Зависимость энергии и ширины полос люминесценции на полувысоте 


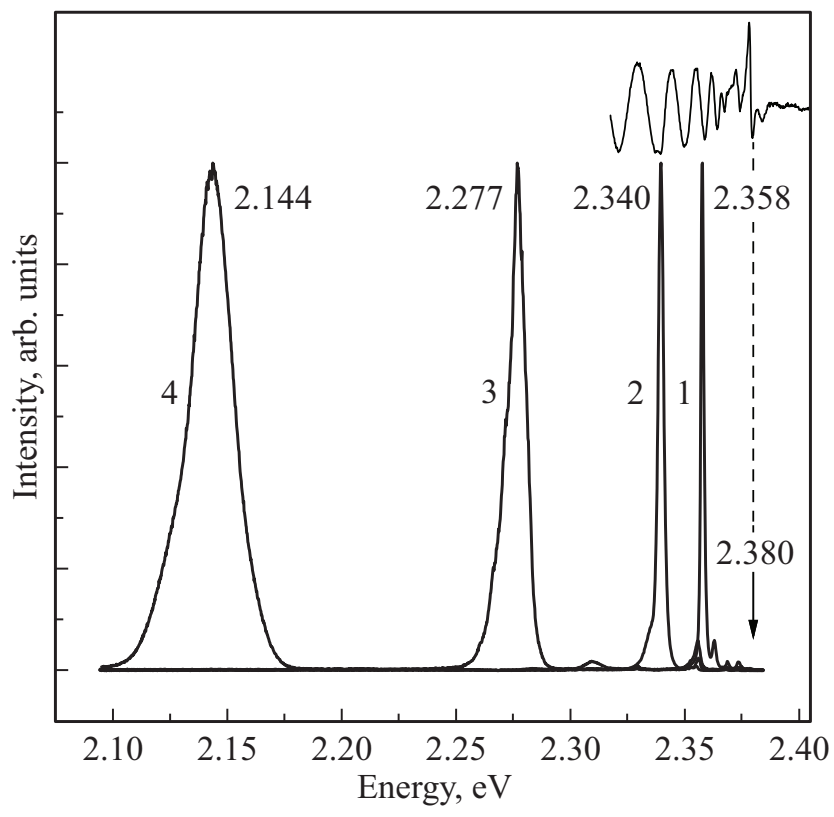

Рис. 1. Нормированные спектры люминесценции образцов № 1-4. Стрелкой показана энергия свободного экситона барьерного слоя ZnTe. Верхняя кривая - спектр отражения образца № $2 . T=5 \mathrm{~K}$.

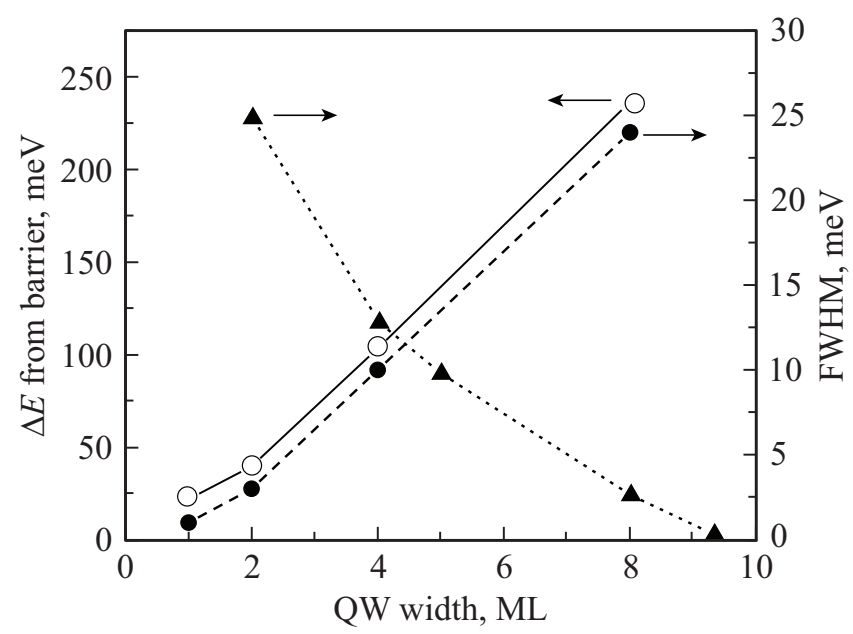

Pис. 2. Энергетическое расстояние $\Delta E$ максимумов полос люминесценции слоев СdTе от энергии свободного экситона барьерного слоя ZnTe и ширина этих полос FWHM в образцах № 1-4 (пустые и заполненные кружки соответственно). Треугольниками показаны значения FWHM полос люминесценции слоев CdTe ненапряженной гетероструктуры $\mathrm{CdTe} / \mathrm{CdMnTe}$ согласно данным работы [11]. На горизонтальной оси указано число монослоев в слое $\mathrm{CdTe} . T=5 \mathrm{~K}$.

их контура (FWHM) от толщины слоя CdTe представлены на рис. 2. Видно, что при росте номинальной толщины слоя от 1 до 8 MC FWHM увеличивается на порядок. Для сравнения приведены аналогичные данные для ненапряженной структуры с КЯ $\mathrm{CdTe} / \mathrm{CdMnTe}$, где с ростом толщины КЯ, напротив, происходит быстрое сужение полосы излучения вследствие уменьшения роли флуктуаций толщины КЯ [11].

Относительные интенсивности излучения слоев CdTe в образцах №№ 1-4 соотносятся следующим образом при температуре $T=5 \mathrm{~K}$ и плотности мощности надбарьерного возбуждения $P=10 \mathrm{~W} \cdot \mathrm{cm}^{-2}$, пиковая интенсивность $-1.0: 1.8: 1.4: 0.85$, интегральная интенсивность - $1.0: 3.2: 8.3: 10.7$.

На основании этих данных с учетом номинальной толщины слоев CdTe (в технологии атомного наслаивания количество атомов кадмия точно контролируется) можно сделать следующие выводы. Резкий рост интегральной интенсивности при увеличении номинальной толщины слоя CdTe от 1 до $4 \mathrm{MC}$ связан с увеличением квантового выхода люминесценции при переходе от двумерной КЯ к планарному массиву КТ. Слабое усиление люминесценции в образце № 4 по сравнению с образцом № 3 можно объяснить тем, что при увеличении количества кадмия возрастают размеры КТ и усиливается их связь друг с другом. Это должно ослаблять локализацию электронного возбуждения и увеличивать вероятность безызлучательной рекомбинации. Сдвиг полосы люминесценции CdTe в сторону низких энергий при увеличении номинальной толщины слоя указывает на то, что размер и/или степень связанности КТ действительно возрастают. Это согласуется с результатами исследований открытых слоев CdTe на ZnTe методом атомно-силовой микроскопии [12,13]. Оценки, сделанные на основании данных работ $[12,13]$, показывают, при увеличении номинальной толщины слоя CdTe от 3 до $4.5 \mathrm{~nm}$ степень заполнения слоя КТ увеличивается от 0.4 до 0.6. Таким образом, в низкоэнергетический сдвиг полосы излучения при росте номинальной толщины слоя CdTe могут дать вклад оба вышеуказанных фактора. Большая величина FWHM полосы излучения слоя CdTe в образце № 4 свидетельствует о том, что при росте номинальной толщины слоя CdTe увеличивается не только средний размер КТ, но и их размерная дисперсия.

Мы исследовали зависимость формы полосы экситонной люминесценции СdTe от уровня оптического возбуждения $P$ (рис. 3). В образцах № 1 и № 2 сильной зависимости формы полосы от уровня возбуждения не наблюдается, что свидетельствует об однородности слоя CdTe. В образце № 4 форма и FWHM контура полосы экситонной люминесценции при $T=5 \mathrm{~K}$ и $P=5 \cdot 10^{2} \mathrm{~W} \cdot \mathrm{cm}^{-2}$ идентичны тем, которые наблюдаются при температуре $110 \mathrm{~K}$ и $P=20 \mathrm{~W} \cdot \mathrm{cm}^{-2}$. Когда $P$ возрастает до $10^{4} \mathrm{~W} \cdot \mathrm{cm}^{-2}$, экситонная полоса сильно уширяется в сторону высоких энергий. Это можно объяснить насыщением нижнего возбужденного состояния КТ и появлением излучения из более высоких состояний, а также увеличением вклада КТ малого размера. В образце № 3 уширение полосы излучения при росте $P$ значительно слабее и имеет иной характер, можно сделать вывод, что параметры ансамблей КТ в образцах № 3 и № 4 существенно различаются. 


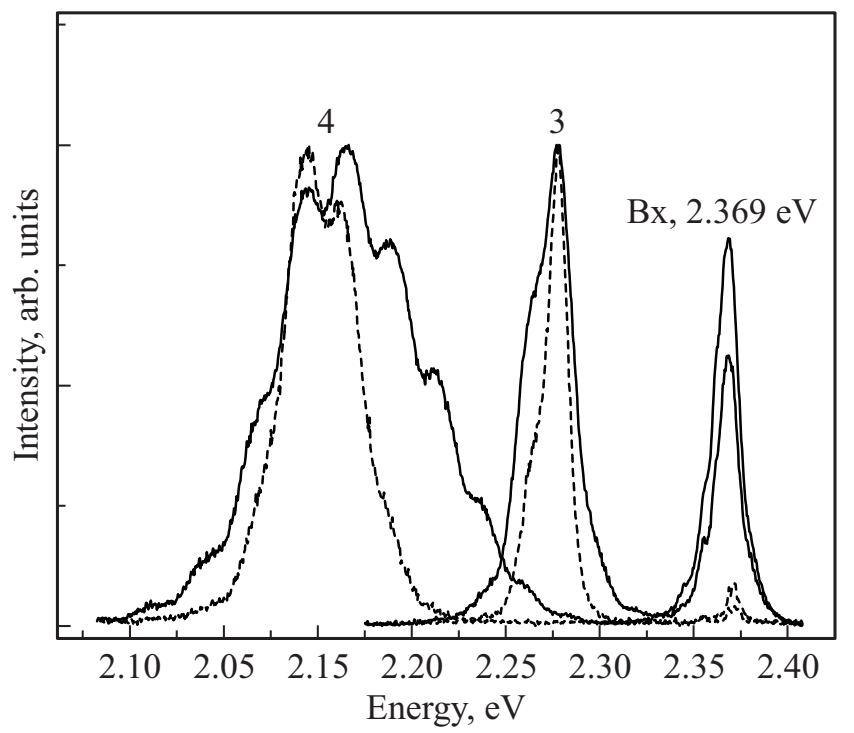

Рис. 3. Спектры фотолюминесценции слоев CdTe и барьерных слоев ZnTe в образцах № 3 и № 4 при плотностях мощности возбуждения $P=20 \mathrm{~W} \cdot \mathrm{cm}^{-2}$ (штриховые линии) и $P=1 \cdot 10^{4} \mathrm{~W} \cdot \mathrm{cm}^{-2}$ (сплошные линии). Спектры нормированы по максимуму интенсивности, $T=5 \mathrm{~K}$. На контур люминесценции образца № 4 налагаются интерференционные полосы слоя ZnTe.

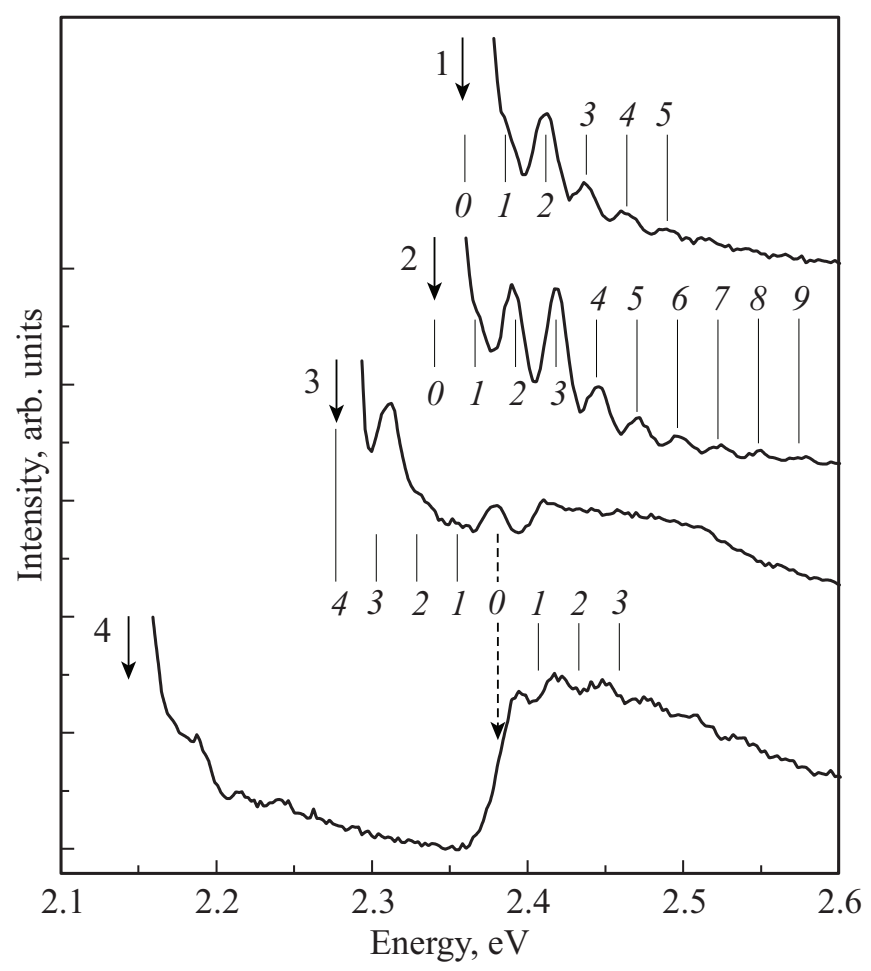

Pис. 4. Спектры возбуждения люминесценции слоев CdTe в образцах № 1-4 при $T=5 \mathrm{~K}$. Сплошными стрелками указаны энергии фотонов, на которых измеряется интенсивность люминесценции, штриховой стрелкой указана энергия $E_{\mathrm{FE}}$ свободного экситона барьерного слоя ZnTe. Сплошные вертикальные линии соответствуют энергиям $E_{\mathrm{FE}} \pm n E_{\mathrm{LO}}$, где $E_{\mathrm{LO}}-$ энергия LO-фонона решетки $\mathrm{ZnTe}, n$ - целое число.
При низком уровне возбуждения в спектре присутствуют узкие линии свободных и мелких связанных экситонов барьерного слоя ZnTe и их фононные повторения. При увеличении $P$ барьерное излучение усиливается по сравнению с излучением слоя $\mathrm{CdTe}$, узкие линии уширяются и сливаются в полосу, максимум которой $3.367 \mathrm{eV}$ соответствует энергии одной из линий связанных экситонов. Обычно при увеличении $P$ люминесценция связанных экситонов насыщается и усиливается излучение свободных экситонов. Отсутствие в нашем случае насыщения люминесценции связанных экситонов можно объяснить тем, что при оптическом возбуждении примесные центры в $\mathrm{ZnTe}$ переходят в такое зарядовое состояние, при котором они эффективно захватывают свободные экситоны.

Спектры возбуждения люминесценции (СВЛ) слоев CdTe в образцах № 1-4, приведенные на рис. 4, существенно отличаются друг от друга. Причиной этого является различие вкладов в перенос энергии в слои $\mathrm{CdTe}$ экситонов барьерного слоя $\mathrm{ZnTe}$ и носителей заряда, не связанных в экситоны (зонные состояния). В том случае, когда преобладает перенос через зонные состояния, в СВЛ наблюдается структура, период которой равен энергии LO фонона $\mathrm{ZnTe} E_{\mathrm{LO}}$.

\section{Образец № 1}

Энергетическое расстояние между уровнями экситонов CdTe и $\mathrm{ZnTe}$ близко к $E_{\mathrm{LO}}$. Передача энергии идет как через экситон $\mathrm{ZnTe}$, так и через зонные состояния, при этом в СВЛ наблюдается фононная структура.

\section{Образец № 2}

Энергетическое расстояние между уровнями экситонов $\mathrm{CdTe}$ и $\mathrm{ZnTe}$ в полтора раза превышает $E_{\mathrm{LO}}$. В этом случае передача энергии через экситон $\mathrm{ZnTe}$ затруднена, слой СdТе заселяется через зонные состояния, и в СВЛ образца № 2 наблюдается наиболее четкая фононная структура.

\section{Образец № 3}

Энергетическое расстояние между уровнями экситонов $\mathrm{CdTe}$ и $\mathrm{ZnTe}$ равно $4 E_{\mathrm{LO}}$. Передача энергии происходит, в основном, через экситон ZnTe, ему соответствует максимум в СВЛ, фононная структура не наблюдается.

\section{Образец № 4}

Энергетическое расстояние между уровнями экситонов CdTe и $\mathrm{ZnTe}$ велико, в СВЛ СdTe экситон $\mathrm{ZnTe}$ не проявляется, заселение слоя CdTе происходит через зонные состояния, интенсивность СВЛ резко падает на краю межзонного поглощения ZnTe. Малость вклада экситона ZnTe в передачу энергии подтверждается тем, 
что в СВЛ СdТе наблюдаются минимумы, которым соответствуют энергии, превышающие энергию экситона $\mathrm{ZnTe}$ на целое число $E_{\mathrm{LO}}$.

\section{3. Выводы}

Спектры люминесценции слоев $\mathrm{CdTe}$, выращенных методом атомного наслаивания в матрице $\mathrm{ZnTe}$, свидетельствуют о том, что слои с номинальной толщиной 1 и $2 \mathrm{MC}$ проявляют свойства, характерные для однородных слоев, а слои с номинальной толщиной 4 и 8 МС являются планарными массивами КТ. Средний размер КТ и их размерная дисперсия возрастают при увеличении номинальной толщины слоя СdТе. Вид СВЛ слоя CdTe зависит от соотношения вкладов в перенос энергии экситона ZnTe и носителей заряда, не связанных в экситон.

\section{Финансирование работы}

Работа выполнена при поддержке научной темы СПбГУ INI 2019 id 36463378 с использованием оборудования Научного парка СПбГУ и гранта 2018/30/M/ST3/00276 National Science Center (Poland).

\section{Конфликт интересов}

Авторы заявляют, что у них нет конфликта интересов.

\section{Список литературы}

[1] V.S. Bagaev, V.V. Zaytsev, V.V. Kalinin, S.R. Oktyabrskii, A.F. Plotnikov. Solid State Commun. 88, 777 (1993).

[2] G. Karczewski, S. Mackowski, M. Kutrowski, T. Wojtowicz, J. Kossut. Appl. Phys. Lett. 74, 3011 (1999).

[3] C. Vargas-Hernández, O. de Melo, I. Hernández-Calderón. Phys. Status Solidi B 230, 331 (2002).

[4] A.M. Kapitonov, U. Woggon, D. Kayser, D. Hommel, T. Itoh. J. Lumin. 112, 177 (2005).

[5] J.S. Kim, H.M. Kim, H.L. Park, J.C. Choi. Solid State Commun. 137, 115 (2006)

[6] T. Kryshtab, J.A. Andraca, L.V. Borkovska, N.O. Korsunska, Ye.F. Venger, Yu.G. Sadofyev. Microlectron. J. 39, 418 (2007).

[7] A. Alfaro-Martinez, I. Hernández-Calderón. Microelectron. J. 39, 594 (2008).

[8] M. Eremenko, G. Budkin, A. Reznitski. JETP 124, 740 (2017).

[9] V. Agekyan, M. Chukeev, G. Karczewski, A. Serov, N. Filosofov, A. Reznitski. Semicond. 53, 2060 (2019).

[10] K. Sawicki, F.K. Malinowski, K. Galkowski, T. Jakubczyk, P. Kossacki, W. Pacuski, J. Suffczinski. Appl. Phys. Lett. 106, 012101 (2015).

[11] D.R. Yakovlev, I.N. Uraltsev, W. Ossau, G. Landwehr, R.N. Bicknell-Tassius, A. Waag, S. Schmeusser. Surf. Sci. 263, 485 (1992).

[12] S.H. Jin, S.H. Kim, J.C. Choi, H.S. Lee. J. Nanosci. Nanotechnology 17, 4132 (2017).

[13] Y.S. No, T.W. Kim, H.S. Lee, H.L. Park. Appl. Surf. Sci. 243, 143 (2005).

Редактор К.В. Емцев 